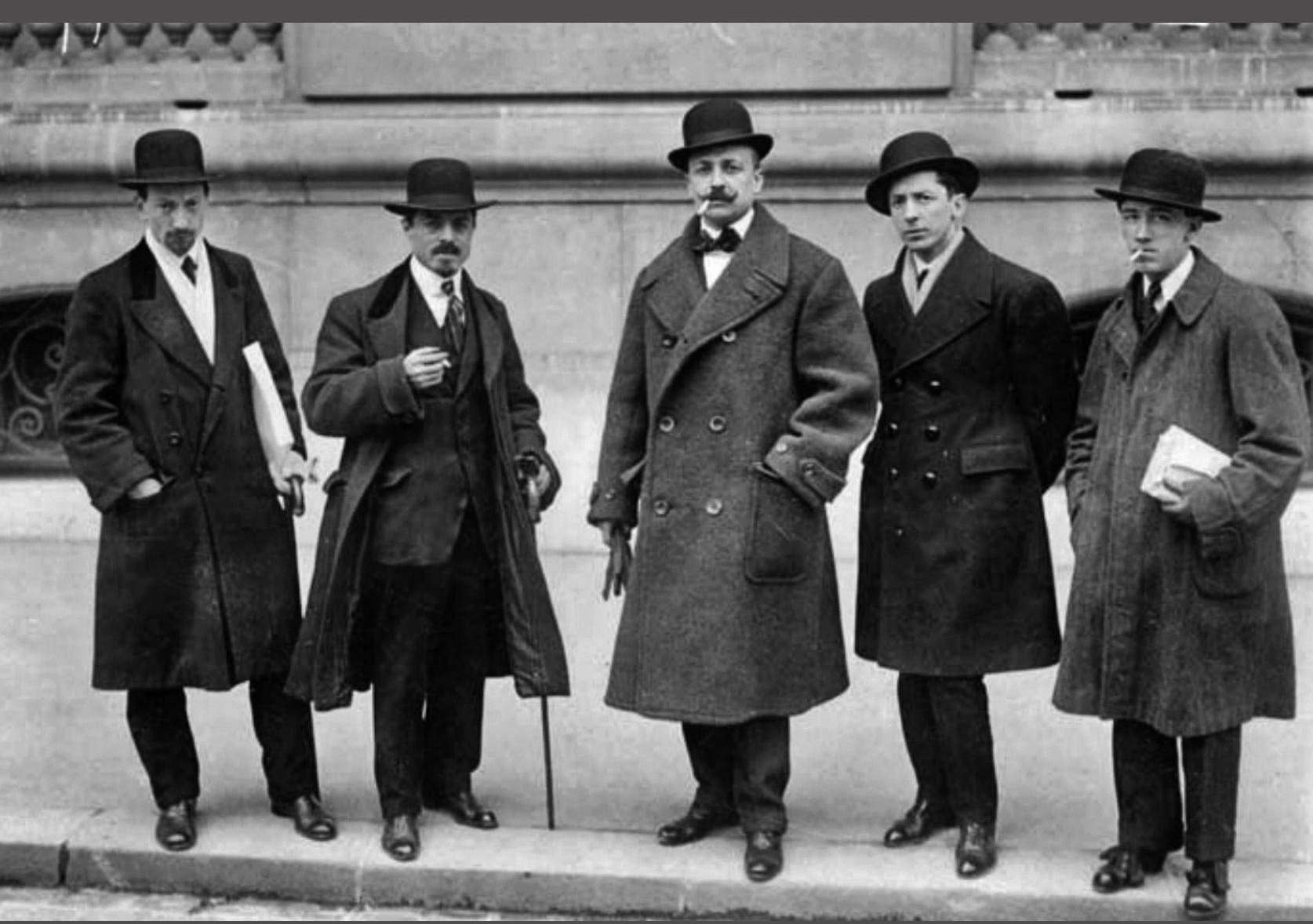

Fig. 1. El grupo futurista en Paris, 1912. De izquierda a derecha: Russolo, Carrá, Marinetti, Boccioni y Severini. 


\title{
Un automóvil de carrera es más bello que la Venus de Samotracia: notas sobre la primera generación futurista
}

\author{
Dr. Alfonso Castrillón Vizcarra \\ Instituto de Investigaciones Museológicas \\ y Artísticas / Universidad Ricardo Palma \\ acastrillon@urp.edu.pe
}

\begin{abstract}
Resumen
En junio de este año el público limeño tuvo la suerte de ver una gran exposición titulada Futurismo y velocidad, auspiciada por la Embajada de Italia y el Instituto Italiano de Cultura en Lima, en el tradicional Museo Italiano, como si las obras hubiesen sido escogidas ad hoc para sus salas. Sin embargo, la extraordinaria colección solo reunía cuadros de una segunda generación de pintores futuristas, presentados por un acertado estudio de Maurizio Scudiero. Animado por esta circunstancia, decidí escribir unas notas sobre el primer futurismo, el de su creador F. T. Marinetti y sus seguidores, sus ideas estéticas, políticas y sus aportes, con el fin de dar al lector los datos para que establezca el puente entre las dos generaciones.
\end{abstract}

Palabras clave: futurismo, pintura futurista, manifiesto, Marinetti, Mussolini

\begin{abstract}
In June of this year, the Lima public was lucky enough to see a large exhibition entitled "Futurismo $y$ velocidad" (Futurism and speed"), sponsored by the Italian Embassy and the Istituto Italiano di Cultura in the traditional Italian Museum, as if the works had been chosen ad hoc for their rooms. However, the extraordinary collection only brought together paintings by a second generation of Futurist artists, introduced by an accurate study by Maurizio Scudiero. Encouraged by this circumstance I decided to write some notes on the first futurism, that of its creator F.T. Marinetti, and his followers, his aesthetic ideas, policies and contributions, in order to give the reader the data to establish the bridge between the two generations.
\end{abstract}

Keywords: Futurism, Futuristic Painting, Manifesto, Marinetti, Mussolini.

\section{Futurismo artístico}

El futurismo nace como un movimiento artístico de vanguardia en Milán, aunque con aspiraciones internacionales, ya que publica su primer manifiesto en el diario Le Figaro, de París, en 1909. Su creador, Filippo Tommaso Marinetti, había nacido en Alejandría (Egipto) en 1876, en el seno de una familia acomodada. Se graduó de Bachellier es lettres en París y siguió estudios de Derecho en Pavía y en Génova. Publicó su primer libro, La conquête des Etoiles, en 1905 y luego la tragicomedia Le Roi Bombance. Pero es sin duda su primer manifiesto el que lo lanzó a la fama, a él y sus amigos artistas. (Marinetti, 1968). 
Mucho se ha escrito sobre el Manifiesto de 1909, que es sin duda una pieza literaria que sorprendió a la escena cultural europea. Hay que tener en cuenta que la obra de Marinetti apareció algunos años antes de las desafiantes presentaciones de los dadaístas en Suiza, y que su autor acertó publicando su texto en un diario como Le Figaro, seguro de obtener abundante rédito publicitario. Marinetti es el poeta de la era industrial con un afinado sentido de la psicología de la información y su Manifiesto -entre poesía y réclame- da cuenta del mundo febril de las grandes capitales europeas, como Milán, su campo de acción.

El Manifiesto comienza con la descripción del paseo de Marinetti y sus amigos en un automóvil por una carretera milanesa: "Habíamos velado toda la noche -mis amigos y yo- bajo lámparas de mezquita de cúpulas de bronce calado, estrelladas como nuestras almas, pues como ellas estaban irradiadas por el cerrado fulgor de un corazón eléctrico" (De Micheli, 1983, p. 369). Marinetti al volante se siente el rey de la pista, la velocidad lo embriaga: "La furibunda escoba de la locura nos arrancó de nosotros mismos y nos lanzó a través de las calles, escarpadas y profundas como lechos de torrentes". Hasta que unos ciclistas se cruzaron y en una maniobra fallida hace que el coche derrape y termine en un foso. El accidente, que pudo terminar en tragedia, es sin embargo para Marinetti un bautismo con aguas estancadas y cualquier gesto cómico queda opacado por la solemnidad con que el autor dice:

iOh! iFoso materno, casi lleno de agua fangosa! iHermoso foso de botica! Degusté ávidamente tu cieno fortificante, que me trajo a la memoria la santa mama negra de mi nodriza sudanesa... Cuando me alcé -andrajo sucio y maloliente- de debajo del coche volcado, me sentí atravesar el corazón, deliciosamente, por el hierro ardiente de la alegría. (De Micheli, 1983, p. 369)

En los once puntos del Manifiesto se advierte la felicidad de Marinetti de ser un hombre del siglo XX en una ciudad como Milán, que despertaba en la era industrial, y en ese escenario va lanzando sus frases desafiantes e hiperbólicas. Se evidencia una actitud y un gesto nuevos: el amor al peligro, la energía, la temeridad, el coraje, la audacia y la rebelión que adornan al hombre eléctrico en su lucha contra la inmovilidad. El movimiento agresivo se traduce en actitudes: el paso de carrera, el salto mortal, la cachetada y el puño en alto; o estados como el insomnio febril del hombre que no quiere perderse nada del espectáculo del mundo nuevo.

Pero también una estética nueva, la belleza de la velocidad, que el ingenio de Marinetti ha hecho famosa: "Un automóvil de carreras con su capó adornado de gruesos tubos semejantes a serpientes de aliento explosivo.... un automóvil rugiente que parece correr sobre la metralla es más bello que la Venus de Samotracia” (De Micheli, 1983, p. 369). La velocidad y la lucha; nada se consigue sin ese esfuerzo: "Solo en la lucha hay belleza", de ahí que la obra de arte debe ser una pelea continua. Y Marinetti va llegando a los extremos; frente a ese chisporroteo de luces que es el nuevo mundo industrial demuestra su desprecio por el pasado: "el tiempo y el espacio murieron" y vocea a gritos la destrucción de la tradición, de los museos, las bibliotecas, las academias. No solo esto, sino que su actitud guerrera frente a la creación artística se mezcla de manera espuria con la política y llega a glorificar la guerra -"única higiene del mundo"- y también el patriotismo, "las bellas ideas por las que se muere" y el desprecio de la mujer. Al final de los once puntos hay una exaltación de las masas de las capitales modernas, de los puertos laboriosos, las estaciones ferroviarias donde pitan felices "las locomotoras de amplio pecho" y truenan los aviones deslizantes; literatura que se convertiría en cuadro gracias a los aportes de Boccioni y sus compañeros.

\section{Los pintores futuristas}

El primer Manifiesto Futurista lo firma solo Marinetti, aunque al inicio del texto hable de que con sus amigos habían "velado toda la noche", se supone que redactándolo. Pero ya en el famoso Contro Venezia passatista, que se volanteó desde la Torre del Reloj en la Plaza 
veneciana en 1910, acompañan a Marinetti, Umberto Boccioni, Carlo Carrá y Luigi Russolo, a los que hay que agregar más tarde los nombres de Gino Severini y Giacomo Balla, que terminan de conformar el grupo de los más allegados al poeta; se podría hablar pues de una primera generación futurista. Nacidos en diferentes regiones de Italia se juntaron en Milán, donde firmaron el Manifiesto de 1910. Algunos partieron del rigor de la Acadamia y del divisionismo de Previati y Segantini, pero la influencia más fuerte la recibieron de la pintura cubista, a consecuencia de sus frecuentes viajes a la capital francesa.

A Giacomo Balla (Torino 18711958) le interesó el problema físico de la luz y su representación, como puede verse en su pintura Lampada ad arco, de 1909; pero también la fotografía estroboscópica, que proviene de Muybridge, de su Dinamismo di un cane al guinzaglio (1912) y Bambina che corre sul balcone (1913). Más adelante se interesó por la pintura abstracta, donde la geometría de las rectas y las curvas buscan una direccionalidad agresiva, como en Mercurio che passa davanti al sole visto dal canochiale (1914). Después del año 20 se convierte en caposcuola (mentor) de la segunda generación futurista. (Drudi Gambillo y Fiori, 1958, p.151).

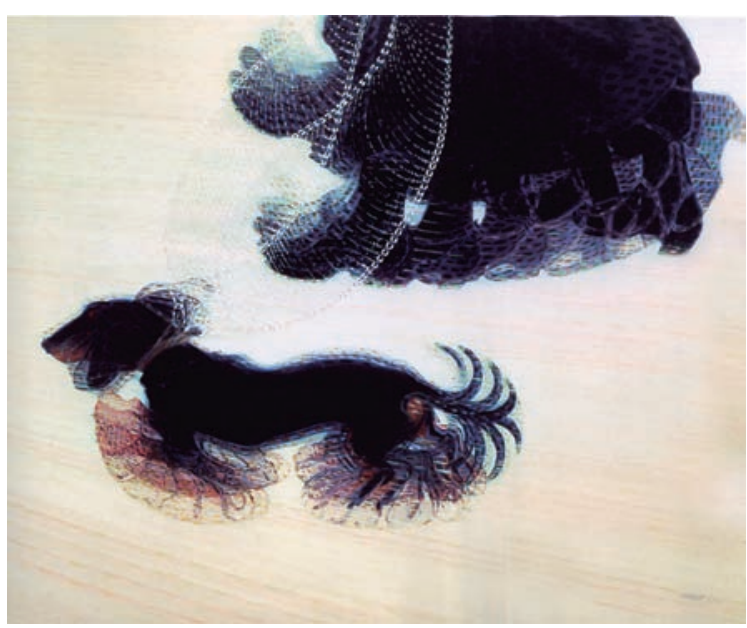

Fig. 2. Dinamismo de un cane al guinzaglio. Balla. Foto: Scudiero

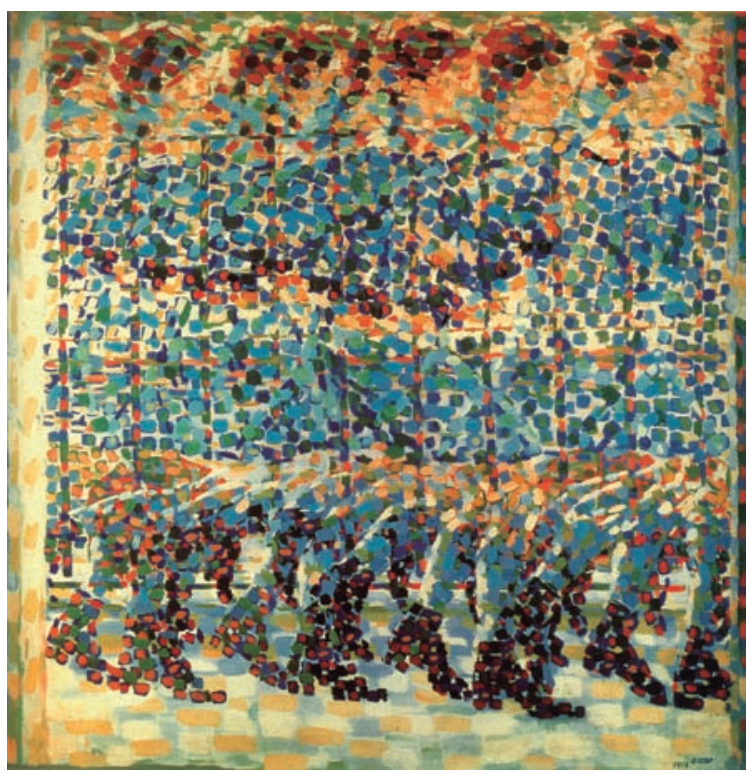

Fig. 3. Bambina che corre sul balcone. Balla. Foto: Scudiero

Umberto Boccioni (Reggio Calabria, 1882-1916), después de un recorrido por varias ciudades italianas se establece en Roma, donde frecuenta la Escuela de Bellas Artes. En 1904 estuvo en Rusia, donde conoció a los artistas vanguardistas, hasta que en 1908 se transfiere a Milán y entra en contacto con Marinetti. Interesado en un principio por los temas de la construcción y de representar el dinamismo de la ciudad industrial que crece, como se nota en su pintura La cittá che sale (1910-1912), se ocupa más tarde por los efectos de la luz sobre la materia, concluyendo que "el movimiento y la luz destruyen la materialidad" y por otro lado que no puede existir pintura sin divisionismo (Drudi Gambillo y Fiori, 1958, p. 66). Esta opinión, además de confirmar la herencia de Previati y Segantini, es coherente con las ideas de Boccioni de una materia en constante movimiento. Como teórico del futurismo, redactó el Manifiesto dei pittori Futuristi (11 de febrero de 1910), La pittura futurista. 


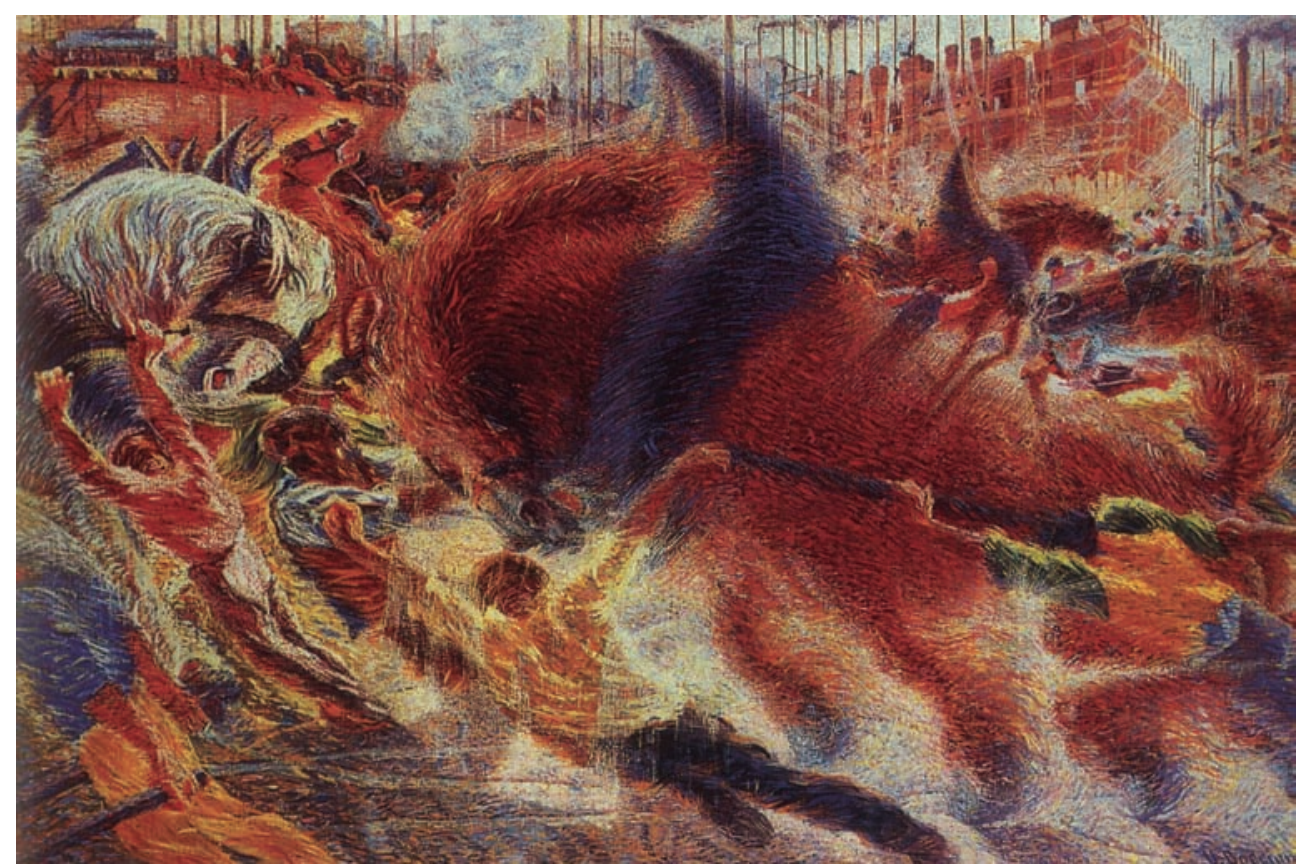

Fig. 4. La cittá che sale. Boccioni.

Foto: Scudieo.

Manifesto técnico (11 de abril de 1910) y La scultura futurista (11 de abril de 1912), donde entre otras cosas dice: "La escultura debe por lo tanto hacer vivir los objetos volviendo sensible, sistemático y plástico su prolongación en el espacio ya que ninguno puede dudar de que un objeto termina donde otro comienza (...)" (Drudi Gambillo y Fiori 1958, p. 69). Se esforzó por demostrar en su pintura, como en la escultura, la idea del movimiento virtual donde los planos se intersecan y descomponen las imágenes a la manera cubista y el divisionismo agrega la vibración cromática. Volvió a la figuración antes de su muerte acaecida en $1916^{1}$.

Si bien los pintores más cercanos a Marinetti firmaron el Manifiesto de la Pintura Futurista de 1910, cada uno escogió su camino y desarrolló un estilo propio, aunque influidos por el divisionismo y el cubismo. El caso de Carlo Carrá (1881-1966) es interesante. Nacido en la provincia de Alessandria, sigue estudios de decoración y luego se transfiere a Milán en 1893. Trabaja en París y Londres hasta que decide seguir los cursos de la Academia Brera (Milán). Es decisivo su encuentro con Boccioni en 1908, con el que firma, más tarde, el Manifiesto de 1910. En 1916 conoce a De Chirico y adhiere a la tendencia metafísica (Drudi Gambillo y Fiori, 1958, p. 293). El cuadro que sigue más de cerca los ideales futuristas es sin duda Los funerales del anarquista Galli, cuyo tema proviene de una experiencia que el propio Carrá vivió durante la huelga anarquista del año 1904. En medio del desorden provocado por los manifestantes y la policía, se observa el uso de la representación estroboscópica señalada por la repetición rítmica de los bastones y las lanzas en medio del fragor de la protesta. Luego de una temporada en que se acerca al cubismo picassiano del año 1911, como La donna e l'assensio (1912), entra de lleno en la metafísica, como puede verse en L'amante del ingeniere, de 1920.

1 Ver Ritratto del maestro Busoni, Milán 1915. Galleria Nazionale d’Arte Moderna, Roma. 
En su manifiesto de 1913, Luigi Russolo (18851947) propone una equivalencia simbólica entre los colores y los sonidos musicales, como se colige de la siguiente afirmación: "Nuestras telas expresarán tanto las equivalencias plásticas de los rumores y de los olores del teatro, del music-hall, del cine, del prostíbulo, de las estaciones ferroviarias, de los puertos, los garajes, las clínicas y las oficinas, etc." (Drudi Gambillo y Fiori 1958, p. 75). Pero es claro que estas equivalencias sirven para comprender sus cuadros, pero no pueden aplicarse a las pinturas de sus compañeros de grupo; es una convención que solo vale para leer su propia pintura.

Pero Russolo (1996) va más lejos; siendo, como declara, un amateur de la música propone, sin embargo, una nueva estética musical. Desde el principio argumenta que "La vida antigua fue toda silencio". Y no hubiera afirmado que "La naturaleza es silen-

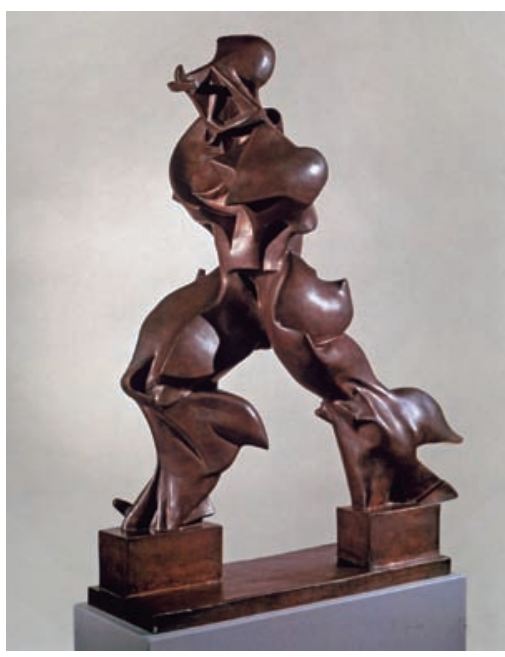

Fig. 5. forme uniche nella continuità dello spazio. Boccioni. Foto: Scudiero. ciosa”, (excepto los ruidos telúricos de erupciones volcánicas, cataratas, tormentas, etc.), si se hubiese internado una noche en un bosque toscano o en la jungla africana. Dice en su manifiesto que la música dedicada al culto se fue convirtiendo en exclusiva de los grupos cerrados, desligada de la vida, hasta que con el tiempo fue dejando los sonidos dulces del

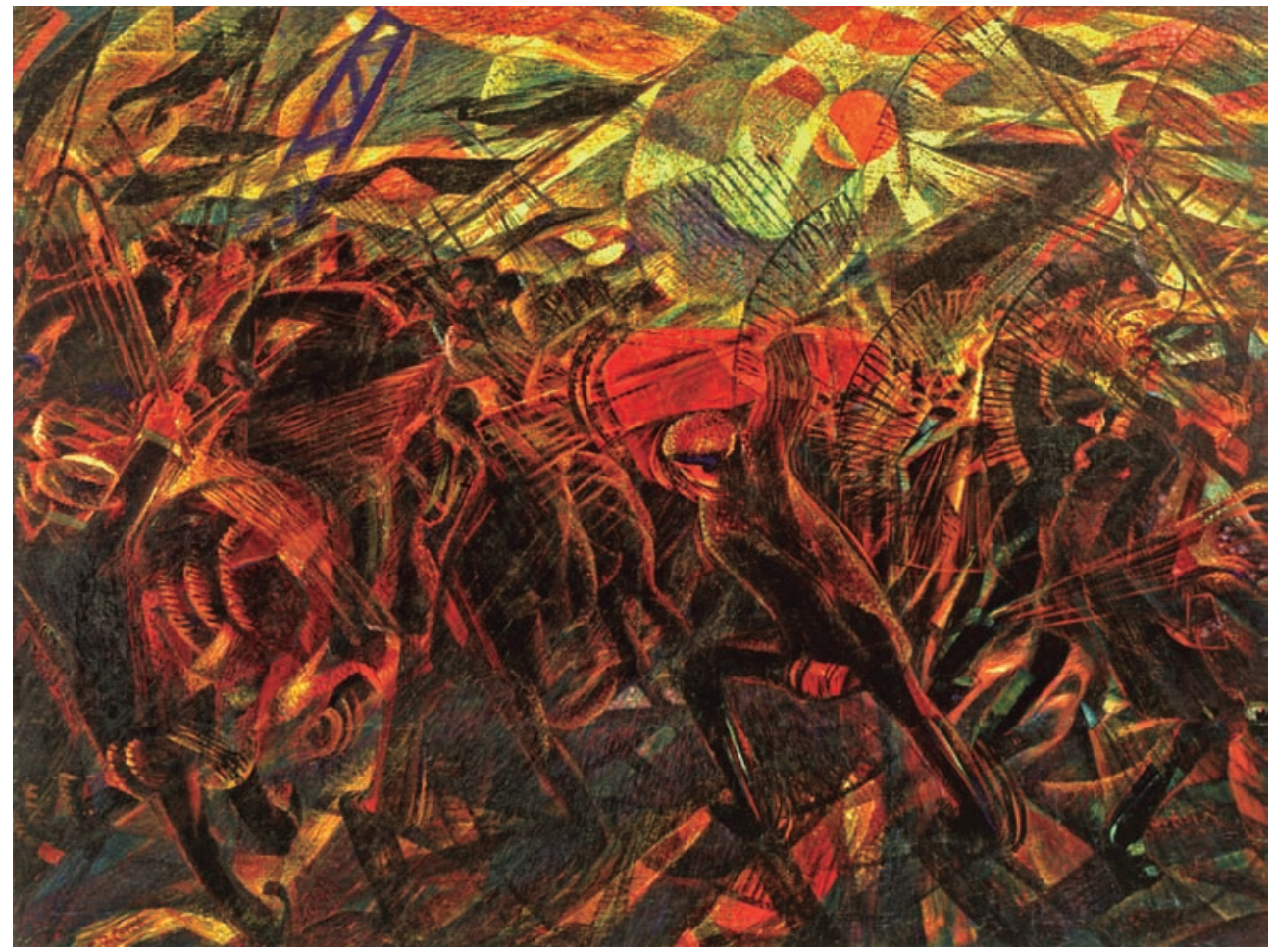

Fig. 6. Los funerales del anarquista Galli. Carrá. Foto: Scudiero. 
Renacimiento por los “disonantes, extraños y ásperos” para el oído, hasta llegar al "sonido ruido" o "ruido musical”. Y más adelante, dentro del estilo marinettiano:

No podemos contemplar el enorme aparato de fuerzas que representa una orquesta moderna sin sentir la más profunda desilusión ante sus mezquinos resultados acústicos. ¿Conocéis acaso un espectáculo más ridículo que el de veinte hombres obstinados en redoblar el murmullo de un violín? (Russolo, 1996, p. 3)

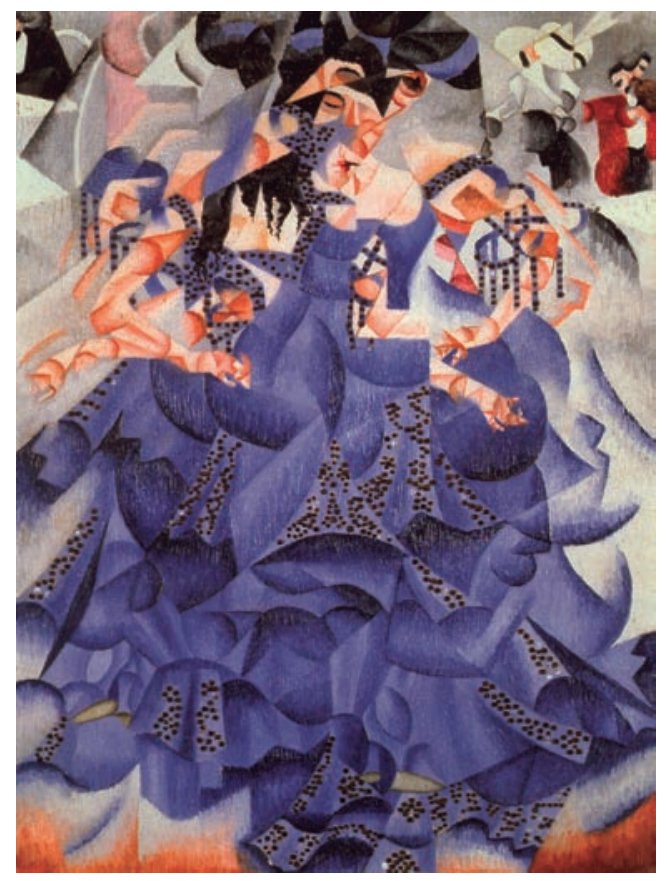

Fig. 7. Bailarina en azul. Severini. Foto: Scudiero.

Sin embargo, a pesar de las bravatas que soltó en sus manifiestos, se puede considerar a Russolo como un precursor de la música concreta y electrónica.

Gino Severini (Cortona, Arezzo 18831966), aunque firmante del Manifiesto de 1910, parece el menos futurista del grupo, por su lenguaje moderado y por su acercamiento al cubismo parisino. Severini afirma que los recuerdos colaboran a intensificar las "emociones plásticas", que sin tener en cuenta el tiempo y el espacio, hacen posible la reunión en un solo conjunto de las realidades percibidas en diferentes lugares. De esta manera, logra en una sola tela cientos de personajes abigarrados que significan encuentros y situaciones distintas para el artista, como en Bailarina en Azul (1910-1912). Severini es el pintor de los coloridos cabarets y del gozo de vivir de una sociedad que agota sus fuerzas antes de la Primera Guerra Mundial y, sin embargo, fue el más longevo del grupo (1958, p. 77) 2 .

\section{Futurismo y política}

El hecho de haber presentado primero a los pintores, puede hacer pensar que al grupo solo lo unía un interés estético. A esta idea colabora el hecho de que cuando se habla de futurismo salta a la vista su colorida pintura publicada en libros y revistas, dejando de lado sus opciones políticas. ¿Cómo estudiarlo sin separar la acción artística de la práctica? Creo que no queda otro camino que seguir la cronología de los hechos para dar la idea de que, por lo menos en su primera época, el futurismo fue un todo de arte y conciencia política.

Como hemos visto líneas arriba, el futurismo se da a conocer gracias a la publicación del Manifiesto de 1909, en París, firmado por Marinetti, pero ya en 1910 aparece el manifiesto Contro Venezia passatista, donde además de la firma del poeta aparecen las de Boccioni, Carrá y Russulo. El tono del texto es agresivo e incitante y el discurso que Marinetti

2 Este trabajo solo ha tenido en cuenta la primera generación de artistas futuristas por ser los más allegados a Marinetti, pero los estudiosos italianos del movimiento agregan la nómina de una segunda generación compuesta por Fortunato Depero, Enrico Prampolini, Ottone Rosai, Mario Sironi y Ardengo Soffici, en los que puede verse una mayor distancia de las fuentes futuristas. El amplio sentido que adquiere con el tiempo la palabra futurismo hace posible que los investigadores crean en la posibilidad de una tercera generación, entre los que podrían estar Baldessari, Cominetti, Conti, Cocco, Dottori, Dudreville, Erba, Evola, Ferrazzi, Funi, Galli, Giannattasio, Ginna, Achile Lega, Magazzini, Marasco, Martini, Morandi, Nannetti, Nannini, Notte, Pannaggi, Venna, etc. Archivi Futurista, vol. 2, p. 403. 
improvisó en el teatro La Fenice terminó en una terrible batalla. Despierta curiosidad saber qué pintaba por entonces Boccioni y qué rumbo tomó su pintura gracias a las intervenciones políticas de Marinetti y el grupo. Boccioni participó en la reyerta de La Fenice, según el texto final del Manifiesto ${ }^{3}$, y parece que se acostumbró a las agresivas manifestaciones de sus compañeros, pero su pintura de esa época no asumió rasgos apologéticos, sino una propuesta que tenía que ver con el crecimiento y la pujanza de la ciudad a punto de convertirse en una metrópolis moderna, como puede verse en Cittá che sale (1910-12) y sus experimentos sobre la visión simultánea. Luigi Russolo, por esa misma época, estaba interesado en denotar la velocidad en sus pinturas y quizás su única respuesta al violentismo de los manifiestos sea La rivolta (1912). La efervescencia política de esos años se deja sentir con más claridad en una pintura ejemplar de Carlo Carrá, Los funerales del anarquista Galli (Milán, 1911), es decir, cuando el artista había cumplido ya los treinta años. A estas alturas habría que averiguar cuál era el compromiso político de Marinetti y sus seguidores para ver si de alguna manera se refleja en sus pinturas.

Desde la publicación del primer manifiesto en 1909, el poeta Marinetti sigue un nutrido programa de actividades que va desde el viaje a París, acompañando a sus amigos pintores en 1912, hasta su viaje a San Petersburgo y Moscú en 1914 (De Michelis, 1973), donde toma contacto con la vanguardia rusa. En 1915 Marinetti (1924) conoce a Mussolini y comparte la cárcel con el futuro líder. Luego viene la participación de los futuristas en la Primera Guerra Mundial; desde el frente, Marinetti escribe ufanándose de "haber hecho correr a los austríacos" y de la superioridad de la artillería italiana $(1958$, p. 32), pero, a pesar de este optimismo en esta guerra voceada como la única higiene del mundo, los futuristas

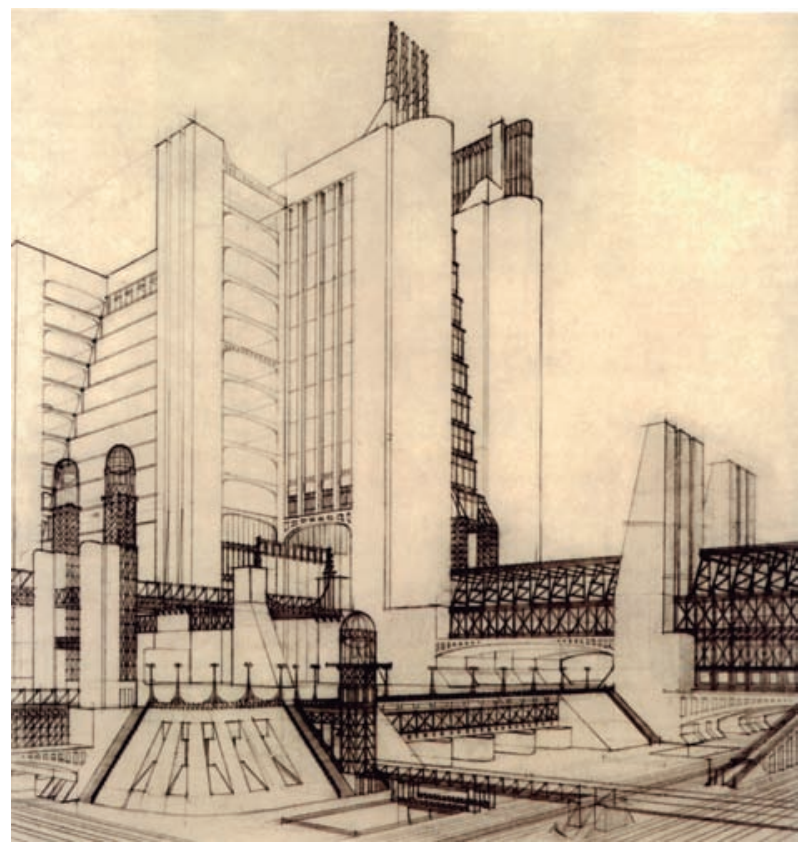

Fig. 8. Architettura. Sant'Elia. Foto: Scudiero.

pierden a uno de sus mejores pintores, Umberto Boccioni, y a una promesa de la arquitectura italiana, Antonio Sant'Elia, de solo 28 años $^{4}$ (Marinetti, 1924, p. 223).

Marinetti durante la guerra se convierte en un obstinado provocador, cree que el conflicto envolverá al mundo entero:

Es decir, un estado agresivo, dinámico, futurista que durará por lo menos diez años. Esta gran guerra, vivida intensamente por los pintores futuristas (...) producirá en

3 "Los pintores futuristas Boccioni, Russolo, Carrá respaldaron este discurso con sonoras cachetadas. Los puños de Armando Mazza, poeta futurista y también un atleta, fueron memorables". Archivi futuristi, vol. 1, p. 21.

4 Boccioni murió en acción al caerse del caballo y Sant'Elia de un tiro en la frente. Russolo también fue alcanzado por una bala en la cabeza pero sobrevivió como Marinetti que, herido, fue condecorado por su participación. 
su sensibilidad verdaderas convulsiones (...) empujándolos a golpear e incitar a los lectores, como ella golpea e incita a los combatientes. (1958, p. 349)

No llama la atención, pues, que desde el frente incite a Severini a "interesarse pictóricamente en la guerra".

El Manifiesto del Partido Político Futurista data de los años 1915 al 1918 y conviene examinarlo para ver cómo las ideas marinettianas pasaron al programa político de los fasci di combattimento.

Los puntos esenciales del manifiesto programático futurista se pueden resumir en: sufragio universal; parlamento y senado técnicos; socialización progresiva de la tierra; expropiación de las tierras incultas y mal cultivadas; nacionalización de las aguas y las minas; industrialización y modernización urbanística; tasación progresiva; progresiva abolición del ejército; justicia gratuita y jueces elegibles; libertad de huelga, de reunión, organización, de prensa; desarrollo económico, civil y de instrucción; ocho horas de trabajo; paridad del trabajo de las mujeres con el de los hombres; anticlericalismo e introducción del divorcio (De Maria, 1968, p. XXXVII).

Según De Maria (1968, p. XXXVI) el acercamiento de los futuristas a Mussolini y su intervención política en los fasci di combatimento va de 1919 y no más allá de la primavera de 1920. Recordemos que Marinetti y Mussolini se conocieron en 1915 y que los futuristas participaron en la campaña interventista con sus típicos métodos de propaganda, como habían hecho en las famosas serate. De María es de la opinión de que el nuevo estilo futurista de imponer a golpes sus ideas pasó directamente a los fascistas. Fue una época donde la colaboración de Marinetti y su grupo con el fascismo resultó frecuente e intensa. ${ }^{6}$ Pero la separación de Marinetti y los futuristas tuvo lugar en la primavera del año 20, en el Congreso de Milán, que significó el giro del movimiento hacia la derecha. Ante los hechos y después de haber tachado a los fascistas de reaccionarios y pasadistas, Marinetti y su grupo dimitieron, "no habiendo podido imponer a la mayoría fascista su tendencia antimonárquica y anticlerical” (De Maria, 1968, p. XXXVII).

Sin embargo, algunos años más tarde Marinetti vuelve al fascismo y a la amistad del Duce, quizás por interés de mantener a su grupo en la actualidad periodística, en el momento en que es elegido Académico (1929). De María (1968) confirma que uno de sus últimos actos políticos tuvo lugar durante la Campaña Nacional, donde tomó con valentía su posición contra el antisemitismo y los detractores del arte moderno, juzgado como degenerado, actitud que, después de todo, sirvió para su reivindicación.

Muertos Boccioni y Sant'Elia, los artistas de la primera generación siguen, unos, el así llamado cubo-futurismo, otros la metafísica ${ }^{7}$, algunos se inician en el paisaje aéreo y la representación de las máquinas como lo sugería el Primer Manifiesto. Cabe ver ahora si el futurismo fue original y el peso de las ideas estéticas de Marinetti tuvo alguna importancia en la historia del arte italiano.

\section{Trascendencia}

Es cierto que el Manifiesto Futurista de 1909 fue la primera manifestación vanguardista del siglo XX, pero también la más agresiva y desconcertante. En una primera lectura se entiende

5 Lettera di F. T. Marinetti a G. Severini, en Arcivi del Futurismo, vol. 1, p. 349.

6 Marinetti participó con Mussolini en la serata (noche) de la Scala el 11 de enero de 1919; estuvo presente en la reunión del fascio milanés del 23 de marzo, en la plaza San Sepolcro, donde dio un discurso; el 15 de abril participó en la batalla de Via Mercante, que terminó con el incendio del diario Avanti, aunque el poeta no tuvo que ver con este último hecho. De María, p. XXXVII.

7 Nombre del movimiento artístico italiano, creado por Giorgio de Chirico, Carlo Carrà, Giorgio Morandi y Filippo De Pisis. 
que es un llamado a la gente joven, una negación del pasado como lastre a favor del desarrollo y el crecimiento de la ciudad moderna y también una toma de posición política. Pero hay en su discurso, es innegable, una tendencia a la hipérbole, al gesto teatral y a la intimidación a fuerza de bravatas de gran efecto, pero irrealizables. La quema de los museos, de las bibliotecas y las academias es una propuesta simbólica y la Ricostruzione futurista del'Universo no es más que una declaración lírica. Preocupantes son, sin embargo, las declaraciones extremas como "queremos glorificar la guerra", de oscuro origen anarquista. Sin embargo, en medio de sus exageraciones podemos encontrar propuestas interesantes como la poética de la velocidad o el tactilismo (Marinetti, 1958, p. 56), una reflexión sobre el sentido del tacto, sustituido siempre por la vista en la apreciación artística, que llevó a Marinetti a "una curación intensiva, localizando los confusos fenómenos de la voluntad y del pensamiento sobre diferentes puntos de (su) cuerpo y particularmente de la palma de la mano", ya que "la insensibilidad de la piel es hasta ahora una mediocre conductora del pensamiento".

Las ideas vanguardistas nacen en Marinetti de una situación de peligro que lo estimula como una droga. Fue así con el Manifiesto (1909) y el episodio de la caída al foso a causa de la velocidad, y también con el Manifiesto técnico de la literatura futurista, donde, volando en una avioneta y entre ascensos y violentas caídas, concibe el texto "con el deseo furioso de liberar las palabras, sacándolas de la prisión del período latino” (Marinetti, 1968, p. 40). La hélice le va dictando: destruir la sintaxis, usar el verbo en infinitivo, la abolición del adjetivo, del adverbio, cómo cada sustantivo debe tener su doble, eliminar la puntuación, destruir la literatura del yo, agregar elementos como el rumor, el peso y el olor hasta ahora descuidados, para por fin llegar a una "psicología intuitiva de la materia" y "romper los viejos obstáculos lógicos y los hilos de plomo de la composición antigua", es decir "la imaginación sin hilos" (Marinetti, 1968, p.46). Es indudable que Marinetti fue uno de los primeros que abrió el camino del irracionalismo en el arte, el de la poesía fonética de los dadaístas y la escritura automática de los surrealistas. El Manifesto fue el medio que utilizaron para propagar sus ideas y Marinetti estimuló constantemente a sus compañeros para que escribieran cada uno sobre su especialidad; ya hemos visto líneas arriba la propuesta de Russolo sobre la música, a la que siguió el texto sobre la arquitectura de Sant'Elia, el de la escenografía de Pranpolini, y el del cine futurista, firmado por Marinetti y otros. El manifiesto fue el medio con el que estos hombres, convencidos de que abrían una nueva época, se lanzarían en busca de una utopía. Si no la alcanzaron políticamente, quedaron sus obras como documentos sobre la sociedad en que vivieron.

\section{Coda: una incógnita}

Quien revise atentamente el número 10 de la revista Amauta $^{8}$, dirigida por José Carlos Mariátegui, encontrará, curiosamente, un artículo sobre el movimiento futurista firmado por F. T. Marinetti, que además incluye una foto suya dedicada al director de la revista. ${ }^{9}$ ¿Qué hace ahí un texto del poeta italiano en medio de artículos sobre el problema de la tierra en el Perú, sobre libertad y propiedad en el nuevo derecho, o sobre el problema religioso en hispanoamérica? Además, sin ninguna información bibliográfica sobre su origen. ¿Por qué lo publicó Mariátegui, sabiendo la distancia política que los separaba? Había criticado a Marinetti y su movimiento desde el año 1921, y refiriéndose a su programa político había dicho que constituía "una de las desviaciones del movimiento, uno de los errores mortales de Marinetti”. Y más adelante invitaba a reírse del italiano "por haber supuesto que un comité de artistas podía improvisar de sobremesa una doctrina política. La ideología política de un artista no puede salir de las asambleas de estetas" (Mariátegui, 1959, p. 58).

8 Amauta, N. ${ }^{\circ}$ 10, Lima, 1927, p. 29.

9 La fotografía no tiene fecha y está firmada dos veces. 
¿De qué trata el texto publicado? No se presenta como un manifiesto; por lo menos no lo dice en ninguna de las dos páginas. El título reza Movimiento Futurista, y abajo "Por F. T. Marinetti”. El primer párrafo lleva por título "La medición futurista” y dice lo siguiente:

Los futuristas pensamos que la crítica en sus formas actuales, usadas por el diario, no responde ya a las necesidades del espíritu moderno enamorado de exactitud, velocidad y simultaneidad. Es necesario suprimirla o modificarla integralmente. Por eso nosotros transformaremos la crítica en medición sintética con epígrafes distintos netamente separados. (Siguen párrafos sobre las características de la crítica futurista). (Anónimo, 1927, p. 29)

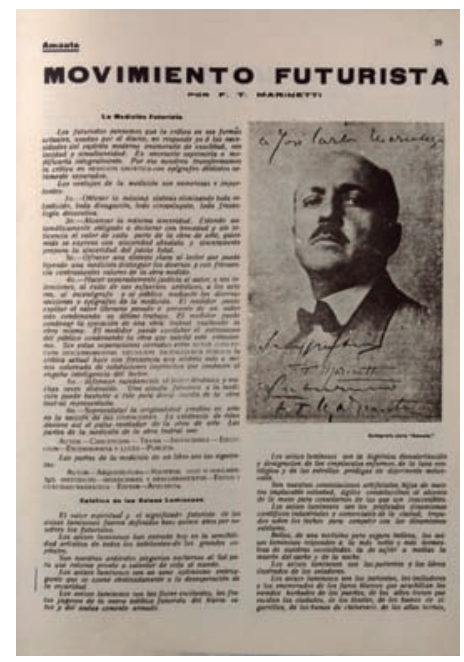

Fig. 9. Revista Amauta $N^{\circ} 10,1927$

El segundo párrafo se titula "Estética de los avisos luminosos", y dice, entre otras cosas: "Los avisos luminosos son la higiénica desvalorización y denigración de los crepúsculos enfermos, de la luna nostálgica y de las estrellas pródigas de deprimente melancolía" (Anónimo, 1927, p. 29). Es curioso que este texto o alguno de sus párrafos no figuren en la edición de los Archivi del Futurismo, por lo que se puede suponer que Mariátegui (1925) lo obtuvo en la época en que estuvo en Italia o, tal vez, llegó a sus manos más tarde, desde Buenos Aires, gracias a sus amigos martinfierristas o a Alberto Hidalgo. ${ }^{10}$ Mientras no se tengan más datos sobre el artículo, quedará como una publicación de favor y una muestra de agradecimiento por el envío de la fotografía, porque lo que pensaba sobre el movimiento ya lo había dicho Mariátegui en sus libros.

Marinetti estuvo dos veces en América: la primera en 1926, promoviendo el futurismo en Brasil, Argentina y Uruguay, donde fue recibido con la sospecha de ser un agente de Mussolini; y la segunda en 1936, en el marco del XIV Congreso Internacional del PEN Club de Buenos Aires (Rabossi, 2010) ${ }^{11}$.

Nos interesa destacar de su primera visita el hecho de que se haya puesto en contacto con el grupo de la revista Martín Fierro y que sus miembros le hayan ofrecido una recepción formal donde, sin embargo, Macedonio Fernández aprovechó la ocasión para burlarse del poeta italiano de manera sutil (Rosa, 2016, p. 56).

De hecho, tanto en Brasil como en Argentina, Marinetti fue mal recibido por su evidente relación con el fascismo mussoliniano, aunque en esa época el poeta ya había atemperado su acción política. En el Perú, el futurismo no tuvo arraigo, a pesar de la prédica fascista de Carlos Miró-Quesada Laos (1937) y "los Polirritmos" de Juan Parra del Riego, que cantan la pasión por las motocicletas y el fútbol (Gonzáles Vigil, 1999).

10 Estas suposiciones se podrían verificar más adelante cuando se investigue con más profundidad las relaciones de Mariátegui con los martinfierristas y el papel que jugó Alberto Hidalgo en la propagación de las ideas del grupo bonaerense.

11 Datos proporcionados gentilmente por el Lic. Julio Meza. 


\section{Referencias bibliográficas}

Anónimo (1927). Amauta, N. ${ }^{\circ}$ 10, p.29, Editorial Minerva.

De Maria, L. (1968). Introduzione. Marinetti, poeta e ideólogo. En Teoría e invenzione futurista. Verona, Italia.

De Micheli. M. (1983). Las vanguardias artísticas del siglo XX. Madrid: Alianza Forma.

De Michelis, C. (1973). Il futurismo italiano in Rusia, 1909-1929. Bari: De Donato.

Drudi Gambillo, M. y Fiori, T. (1958). Archivi del Futurismo, vols. 1 y 2. Roma: De Luca Editore.

González Vigil, R. (1999). Poesía Peruana del siglo $X X$. Lima: Editorial PetroPerú.

Mariátegui, J. C. (1925). La escena contemporánea. En Obras Completas (Vol. 1). Lima: Amauta.

Mariátegui, J. C. (1959). El artista y la época. En Obras Completas (Vol. 6). Lima: Amauta.

Marinetti, F. T. (1924). Il futurismo e la guerra. En Futurismo e fascismo. Italia: Foglino.

Marinetti, F. T. (1958). L'Orgoglio italiano. Manifesto futurista. En Archivi del Futurismo. (Vol. 1, p.32). Roma, Italia.
Marinetti, F. T. (1958). Il tattilismo. Manifesto Futurista. En Archivi del Futurismo. (Vol. 1, p. 56). Roma, Italia.

Marinetti F. T. (1968). Teoria e invenzione futurista. Verona: Editorial Mondadori.

Miró-Quesada Laos, C. (1937). Intorno agli scritti e discorsi de Mussolini. Con introduzione di José de la Riva-Agüero. Milano: Fratelli Treves Editori.

Rabossi, C. (2010). Los viajes de Marinetti por América del Sur. En La Nación, 10 de abril del 2010. Buenos Aires, Argentina.

Rosa, L. O. (2016). Comienzos para una estética anarquista, Borges y Macedonio. Providencia, Santiago: Editorial Cuarto Propio.

Russolo, L. (1996). El arte de los ruidos. Manifiesto Futurista. En Revista Sin Título, N. ${ }^{\circ}$ 3. Facultad de Bellas Artes, Universidad de Castilla-La Mancha, España.

Severini. G. (1985). Le analogie plastiche del dinamismo. Manifesto futurista. En Archivi del Futurismo. (Vol. 1). Roma, Italia. 